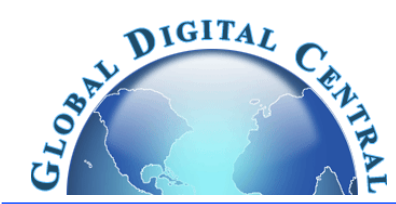

Frontiers in Heat and Mass Transfer

Available at www.ThermalFluidsCentral.org

\title{
STEADY-STATE TRANSPORT PHENOMENA ON INDUCED MAGNETIC FIELD MODELLING FOR NON-NEWTONIAN TANGENT HYPERBOLIC FLUID FROM AN ISOTHERMAL SPHERE WITH SORET AND DUFOUR EFFECTS
}

\author{
A. Subba Rao ${ }^{* a,}$ L. Nagaraja ${ }^{\mathrm{a}, \mathrm{b}}$, M. Sudhakar Reddy ${ }^{\mathrm{a}}$, M. Surya Narayana Reddy \\ ${ }^{a}$ Department of Mathematics, Madanapalle Institute of Technology \& Science, Madanapalle, 517325, INDIA. \\ ${ }^{b}$ Department of Mathematics, JNTUA College of Engineering, Pulivendula,516390 ,INDIA,
}

\begin{abstract}
This article investigates the theoretical steady magneto hydrodynamic heat flow of incompressible non-Newtonian Tangent Hyperbolic fluid flow over a sphere with Soret and Dufour effects. The governing coupled non-linear partial differential equations are reduced to non-similarity boundary layer equations using appropriate transformation and then solved using the finite difference Keller-Box method. The effect of various flow parameters on the velocity, temperature and concentration are analyzed and presented graphically.

Keywords: Tangent Hyperbolic Fluid, MHD, Heat Transfer, Isothermal Sphere, Soret and Dufour effects
\end{abstract}

\section{INTRODUCTION}

Coating hydrodynamics has been an area of considerable interest since the monumental paper by Landau and Levich (1942) in which an elegant formulation was developed for the thickness of the film of a fluid which is deposited on a plate withdrawn vertically from a bath at constant velocity. This work was however confined to Newtonian viscous fluids. In many modern industries non-Newtonian fluids are encountered e.g. in polymer coating processes (Lawrence and Zhou, 1991). Numerous researchers have therefore investigated coating dynamics of different stationary or rotating geometrical bodies (plates, cones, spheres, cylinders) with non-Newtonian liquids and have employed a range of mathematical constitutive equations. Jenekhe and Schuldt (1984) studied coating flows of power-law and Carreau fluids on spinning disks. Campanella et al. (1986) investigated dip coating of a circular cylinder in non-Newtonian power-lawfluids. Zevallos et al. (2005) presented a finite element simulation of forward roll coating flows of viscoelastic liquids using both Oldroyd-B and FENE-P models. These studies however ignored heat transfer which may be critical in certain coating systems (Mitsoulis, 1986). The diffusion of heat can modify polymer properties significantly (Mark, 1996). Several authors have therefore studied thermo fluid transport in non-Newtonian external coating flows. Prasad et al. (2013) and Subba Rao et al. (2016) investigated computationally the momentum and heat transfer characteristics in external boundary layer slip flow of a viscoplastic fluid from a cylinder. The classical Navier-Stokes theory does not describe sufficiently the flow properties of polymeric fluids, colloidal suspensions, and fluids having certain additives.

Transport from external surfaces of curved bodies', e.g. vertical cones has also stimulated some interest in recent years. Such flows are of relevance to chemical engineering systems and also materials synthesis. Cheng (2015) studied the free convection heat transfer from a non-isothermal permeable cone with suction and temperaturedependent viscosity. Sulochana et al. (2016) analyzed the momentum, heat and mass transfer behavior of magneto hydrodynamic flow towards a vertical rotating cone in porous medium with thermophoresis and Brownian motion effects. Cheng (2015) examined the natural convection heat transfer about a vertical cone embedded in a porous medium with isothermal wall conditions. Yih (1999) studied the effect of thermal radiation flux on free convection about a truncated cone. Gorla et al. (1986) investigated the micropolar convection boundary layer flow from a cone.

An interesting model in non-Newtonian fluid mechanics is viscoelastic Jeffrey fluid model. This model degenerates to a Newtonian fluid at a very high wall shear stress. This fluid model also approximates reasonably well the rheological behavior of a wide range of industrial liquids including biotechnological detergents, physiological suspensions, foams, geological material, cosmetics, syrups, etc. Many researchers have explored a range of industrial and biological flow problems using the Jeffery model. Prasad et al. (2014) and Subba Rao et al. (2015) studied external Jeffery viscoelastic boundary layer flow from a circular cylinder using an implicit finite difference code and showed that with increasing Deborah numbers there is a fall in Nusselt number (heat transfer rate) and the skinfriction coefficient.

The number of researchers worked on non-Newtonian fluids. Examples of such fluids include coal-oil slurries, shampoo, paints, grease, cosmetic products, custard, and physiological liquids. The classical equations employed in simulating Newtonian viscous flows i.e. the Navier-Stokes equations fail to simulate a number of characteristics of non-Newtonian fluid. Recent investigations have implemented, Muhammad Naseer et al. (2014) analyzed the boundary layer flow of hyperbolic tangent fluid over a vertical exponentially stretching cylinder. Nadeem et al. (2015) are investigated Effects of nanoparticles on the peristaltic motion of tangent hyperbolic fluid 
model in an annulus. MHD on tangent hyperbolic fluids also investigated M. Ali Abbas et al. (2016), Salahuddin et al. (2015), Satya Narayana et al. (2016). In present communication, we address the convective heat transfer conditions in the radiative flow of Tangent hyperbolic fluid in isothermal sphere. Soret and Dufour effects are taken into account. The effect of heat transfer in dynamics of fluid flows is an interesting recent area of research recently. These effects are turned over during study of power industry problem like nuclear waste disposal, energy transfer in a wet cooling tower, geothermal energy process etc. It is well known that the energy fluxes are yielded not only by the temperature gradients but also by the concentration gradients. If the energy fluxes (heat transfer) are made by concentration gradients, this phenomenon is called the diffusion-thermo or Duffer effect. On the other hand, mass fluxes are made by temperature gradients is called Soret or thermal diffusion effect. Recently the effects of Soret and Dufour are considered to investigate the various interesting problems, Qasim, et al. (2014), S. Panigrahi, et al. (2014), T. Hayat et al. (2014).

Hereafter, the objective of this paper is to study an MHD free convection flow along an isothermal sphere in the presence of Soret and Dufour effects. The governing equations are transformed by using steady non-similarity transformation and the resulting dimensionless calculations are solved numerically using the finite difference KellerBox technique. The effects of various governing parameters on the velocity, temperature, concentration are achieved.

\section{NON-NEWTONIAN CONSTITUTIVE TANGENT HYPERBOLIC FLUID MODEL}

In the present study a subclass of non-Newtonian fluids known as the Tangent Hyperbolic fluid model is employed owing to its simplicity. The Cauchy stress tensor, in the Tangent Hyperbolic non-Newtonian fluid Pop, 2001, takes as follows: $\bar{\tau}=\left[\mu_{\infty}+\left(\mu_{0}+\mu_{\infty}\right) \tanh (\Gamma \overline{\dot{\gamma}})^{n}\right] \overline{\dot{\gamma}}$

Where $\bar{\tau}$ is extra stress tensor, $\mu_{\infty}$ is the infinite shear rate viscosity, $\mu_{0}$ is the zero shear rate viscosity, $\Gamma$ is the time dependent material constant, $\mathrm{n}$ is power law index i.e. flow behavior index and $\overline{\dot{\gamma}}$ is define as:

$\overline{\dot{\gamma}}=\sqrt{\frac{1}{2} \sum_{i} \sum_{j} \overline{\dot{\gamma}}_{i j} \overline{\dot{\gamma}}_{j i}}=\sqrt{\frac{1}{2} \Pi}$ where $\Pi=\frac{1}{2} \operatorname{tr}\left(\operatorname{grad} V+(\operatorname{grad} V)^{T}\right)^{2}$.

We consider Eq. (1), for the case when $\mu_{\infty}=0$ because it is not possible to discuss the problem for the infinite shear rate viscosity and since we are considering tangent hyperbolic fluid that describes shear thinning effects so $\Gamma \overline{\dot{\gamma}} \ll 1$. The Eq. (1) takes the form

$$
\begin{aligned}
\bar{\tau} & =\mu_{\infty}\left[(\Gamma \overline{\dot{\gamma}})^{n}\right] \overline{\dot{\gamma}}=\mu_{\infty}\left[(1+\Gamma \overline{\dot{\gamma}}-1)^{n}\right] \overline{\dot{\gamma}} \\
& =\mu_{\infty}\left[1+n(\Gamma \overline{\dot{\gamma}}-1)^{n}\right] \overline{\dot{\gamma}}
\end{aligned}
$$

The introduction of appropriate terms into the flow model is considered next. The resulting boundary value problem is found to be well-posed and permits an excellent mechanism for the assessment of rheological characteristics on the flow behavior.

\section{MATHEMATICAL FORMULATION}

We consider a steady, two dimensional free convective heat transfers along the isothermal sphere embedded in non-Newtonian Tangent Hyperbolic fluid. The $\mathrm{x}$-coordinate (tangential) is measured along the surface of the sphere from the lowest point and the y-coordinate (radial) is directed perpendicular to the surface, with a denoting the radius of the sphere. $r(x)=a \sin (x / a)$ is the radial distance from the symmetrical axis to the surface of the sphere. The equations for mass, momentum, energy and concentration can be written as follows:

$$
\begin{aligned}
& \frac{\partial(r u)}{\partial x}+\frac{\partial(r v)}{\partial y}=0 \\
& u \frac{\partial u}{\partial x}+v \frac{\partial u}{\partial y}=v(1-m) \frac{\partial^{2} u}{\partial y^{2}}+\sqrt{2} v m \Gamma \frac{\partial u}{\partial y} \frac{\partial^{2} u}{\partial y^{2}} \\
& +g \beta\left(T-T_{\infty}\right) \sin (x / a)+g \beta^{*}\left(C-C_{\infty}\right) \sin (x / a)-\frac{\sigma B_{0}^{2}}{\rho} u \\
& u \frac{\partial T}{\partial x}+v \frac{\partial T}{\partial y}=\alpha \frac{\partial^{2} T}{\partial y^{2}}+\frac{D_{m} K_{T}}{c_{s} c} \frac{\partial^{2} C}{\partial y^{2}} \\
& u \frac{\partial C}{\partial x}+v \frac{\partial C}{\partial y}=D_{m} \frac{\partial^{2} C}{\partial y^{2}}+\frac{D_{m} K_{T}}{T_{m}} \frac{\partial^{2} T}{\partial y^{2}}
\end{aligned}
$$

where $\mathrm{u}$ and $\mathrm{v}$ are the velocity components in the $\mathrm{x}$ - and $\mathrm{y}$ directions respectively, $v=\mu / \rho$ is the kinematic viscosity of the Tangent Hyperbolic fluid, $\beta$ is the coefficient of thermal expansion, $\alpha$ is the thermal diffusivity, $\beta$ is the temperature, and $\rho$ is the density of the fluid. The Tangent Hyperbolic fluid model therefore introduces a mixed derivative (second order, first degree) into the momentum boundary layer Eq. (2). Boundary conditions are:

$$
\begin{aligned}
& \text { As } y=0: u=0, \quad v=-v_{w}, T=T_{w} \\
& \text { At } y \rightarrow \infty: u \rightarrow 0, \quad T \rightarrow T
\end{aligned}
$$

Here $T_{\infty}$ is the free stream temperature, $\mathrm{k}$ is the thermal conductivity, $h_{w}$ is the convective heat transfer coefficient, and $T_{w}$ is the convective fluid temperature. The stream function $\psi$ is defined by $r u=\frac{\partial(r \psi)}{\partial y}$ and $r v=-\frac{\partial(r \psi)}{\partial x}$, and therefore, the continuity equation is automatically satisfied.

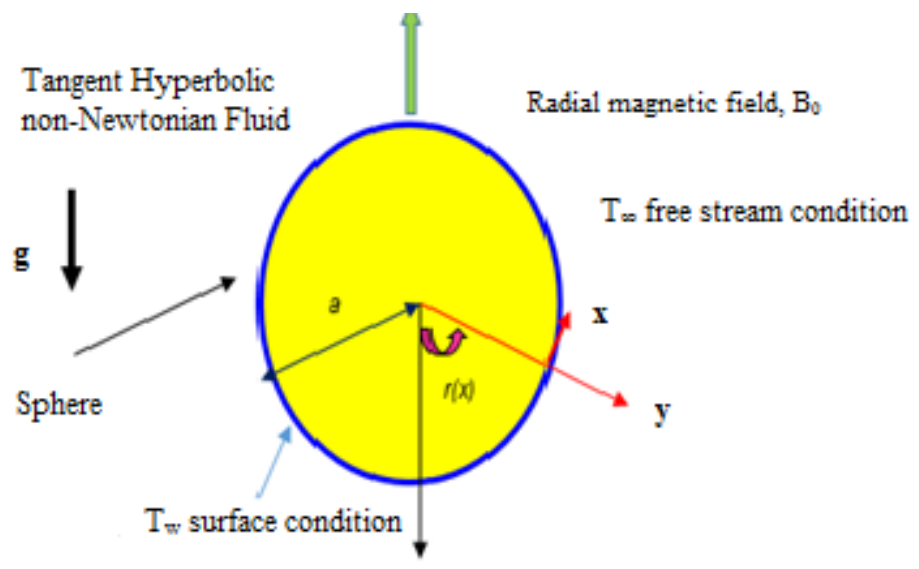

Fig. 1 Physical model and coordinate system

In order to render the governing equations and the boundary conditions in dimensionless form, the following non-dimensional quantities are introduced:

$\xi=\frac{x}{a} \quad \eta=\frac{y}{a} G r^{1 / 4}, \quad \psi=v \xi G r^{1 / 4} f, \quad \theta=\frac{T-T_{\infty}}{T_{w}-T_{\infty}}$, 
$\phi=\frac{C-C_{\infty}}{C_{w}-C_{\infty}}, M=\frac{\sigma B_{0}^{2} a^{2}}{\rho v G r^{1 / 2}}, \operatorname{Pr}=\frac{v}{\alpha}, S c=\frac{D_{m}}{v}$

The terms are defined on nomenclature. In view of the transformations defined in (6). The boundary layer equations (2)-(4) are reduced to the following nonlinear, dimensionless partial differential equations for momentum, energy and concentration for the regime:

$$
\begin{array}{r}
(1-m) f^{\prime \prime \prime}-f^{\prime 2}+(1+\xi \cot \xi) f f^{\prime \prime}+W e m f^{\prime \prime} f^{\prime \prime \prime}-M f^{\prime} \\
+\frac{\sin \xi}{\xi}(\theta+N \phi)=\xi\left(f^{\prime} \frac{\partial f^{\prime}}{\partial \xi}-f^{\prime \prime} \frac{\partial f}{\partial \xi}\right) \\
\frac{1}{\operatorname{Pr}} \theta^{\prime \prime}+D u \phi^{\prime \prime}+(1+\xi \cot \xi) f \theta^{\prime}=\xi\left(f^{\prime} \frac{\partial \theta}{\partial \xi}-\theta^{\prime} \frac{\partial f}{\partial \xi}\right) \\
\frac{1}{S c} \phi^{\prime \prime}+\operatorname{Sr} \theta^{\prime \prime}+(1+\xi \cot \xi) f \phi^{\prime}=\xi\left(f^{\prime} \frac{\partial \phi}{\partial \xi}-\phi^{\prime} \frac{\partial f}{\partial \xi}\right)
\end{array}
$$

The transformed dimensionless boundary conditions are as follows:

At $\eta=0: \quad f=0, \quad f^{\prime}=0, \quad \theta=1$

As $\eta \rightarrow \infty: \quad f^{\prime} \rightarrow 0, \quad \theta \rightarrow 0$

Here, primes denote the differentiation with respect to $\eta$; $D u=\frac{D_{m} K_{T}}{v C_{S} C_{p}} \frac{C_{w}-C_{\infty}}{T_{w}-T_{\infty}}$ and $S r=\frac{D_{m} K_{T}}{v T_{m}} \frac{T_{w}-T_{\infty}}{C_{w}-C_{\infty}}$ are the nondimensional Soret and Dufour effects, respectively. The skin friction coefficient (shear stress at the sphere surface) and Nusselt number (heat transfer rate) can be defined using the transformations described above with the following expressions.

$$
\begin{aligned}
& G r^{-3 / 4} C_{f}=(1-m) \xi f^{\prime \prime}(\xi, 0)+\frac{m}{2} W e \xi\left(f^{\prime \prime}(\xi, 0)\right)^{2} \\
& G r^{-3 / 4} N u=-\theta^{\prime}(\xi, 0)
\end{aligned}
$$

\section{NUMERICAL SOLUTION WITH KELLER-BOX IMPLICIT METHOD}

The Keller-Box implicit difference method is implemented to solve the nonlinear boundary value problem defined by eqns. (7)-(9) with boundary conditions (10). This technique despite recent developments in other numerical methods as elaborated by Keller, 1978. The Keller Box Scheme comprises four stages.

1. Decomposition of the Nth order partial differential equation system to $\mathrm{N}$ first order equations.

2. Finite Difference Discretization.

3. Quasilinearization of Non-Linear Keller Algebraic Equations and finally.

4. Block-tridiagonal Elimination solution of the Linearized Keller Algebraic Equations.

\section{Stage1: Decomposition of $\mathrm{N}^{\text {th }}$ order partial differential equation system to $\mathbf{N}$ first order equations}

Equations (6)-(7) subject to the boundary conditions (8) are first cast as a multiple system of first order differential equations. New dependent variables are introduced $u(x, y)=f^{\prime}, v(x, y)=f^{\prime \prime}, \quad s(x, y)=\theta, t(x, y)=\theta^{\prime}, p(x, y)=\phi^{\prime}(13)$. These denote the variables for velocity, temperature respectively. Now equations (6)-(7) are solved as a set of fifth order simultaneous differential equations:

$$
\begin{aligned}
& f^{\prime}=u \\
& u^{\prime}=v \\
& \theta^{\prime}=t \\
& \phi^{\prime}=p \\
& (1-m) v^{\prime}-u^{2}+(1+\xi \cot \xi) f v+m W e v v^{\prime}-M u+ \\
& \frac{\sin \xi}{\xi}(s+N g)=\xi\left(u \frac{\partial u}{\partial \xi}-v \frac{\partial f}{\partial \xi}\right) \\
& \frac{1}{\operatorname{Pr}} t^{\prime}+D u p^{\prime}+(1+\xi \cot \xi) f t=\xi\left(u \frac{\partial s}{\partial \xi}-t \frac{\partial f}{\partial \xi}\right) \\
& \frac{1}{S c} p^{\prime}+S r t^{\prime}+(1+\xi \cot \xi) f p=\xi\left(u \frac{\partial g}{\partial \xi}-p \frac{\partial f}{\partial \xi}\right)
\end{aligned}
$$

where primes denote differentiation with respect to a variable $\eta$. In terms of the dependent variables, the boundary conditions assume the form:

$$
\begin{array}{ll}
\text { At } \eta=0: & f=0, \quad f^{\prime}=0, \quad \theta=1 \\
\text { As } \eta \rightarrow \infty: & f^{\prime} \rightarrow 0 \quad \theta \rightarrow 0
\end{array}
$$

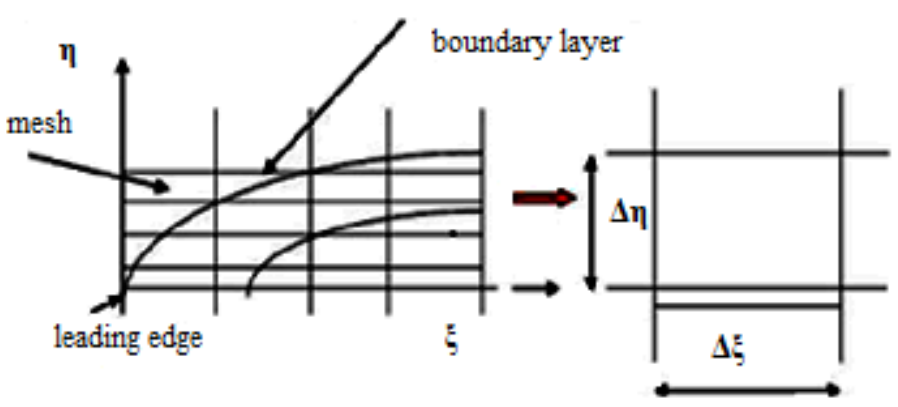

Fig. 2 Keller box computational domain

\section{Stage 2: Finite Difference Discretization}

A two dimensional computational grid is imposed on the $\xi-\eta$ plane as sketched in Fig. 2. The stepping process is defined by:

$$
\begin{aligned}
& \eta_{0}=\eta_{j-1}+h_{j}, \quad j=1,2,3, \ldots, J, \quad \eta_{j}=\eta_{\infty} \\
& \xi^{0}=0, \quad \xi^{n}=\xi^{n-1}+k_{n} \quad n=1,2,3, \ldots, N \\
& g_{j-1 / 2}^{n-1 / 2}=\frac{1}{4}\left(g_{j}^{n}+g_{j-1}^{n}+g_{j}^{n-1}+g_{j-1}^{n-1}\right) \\
& \left(\frac{\partial g}{\partial \eta}\right)_{j-1 / 2}^{n-1 / 2}=\frac{1}{2 h_{j}}\left(g_{j}^{n}-g_{j-1}^{n}+g_{j}^{n-1}-g_{j-1}^{n-1}\right) \\
& \left(\frac{\partial g}{\partial \xi}\right)_{j-1 / 2}^{n-1 / 2}=\frac{1}{2 k}\left(g_{j}^{n}-g_{j-1}^{n}+g_{j}^{n-1}-g_{j-1}^{n-1}\right), \\
& h_{j}^{-1}\left(f_{j}^{n}-f_{j-1}^{n}\right)=u_{j-1 / 2}^{n}, \\
& h_{j}^{-1}\left(u_{j}^{n}-u_{j-1}^{n}\right)=v_{j-1 / 2}^{n}
\end{aligned}
$$


$h_{j}^{-1}\left(s_{j}^{n}-s_{j-1}^{n}\right)=t_{j-1 / 2}^{n}$

$h_{j}^{-1}\left(g_{j}^{n}-g_{j-1}^{n}\right)=p_{j-1 / 2}^{n}$,

$(1-m)\left(v_{j}-v_{j-1}\right)-(1+\alpha) \frac{h_{j}}{4}\left(u_{j}+u_{j-1}\right)^{2}$

$+(1+\alpha+\xi \cot \xi) \frac{h_{j}}{4}\left(f_{j}+j_{j-1}\right)\left(v_{j}+v_{j-1}\right)$

$+\frac{\sin \xi}{\xi} \frac{h_{j}}{2}\left(\left(s_{j}+s_{j-1}\right)+N\left(g_{j}+g_{j-1}\right)\right)$

$-m \frac{W e}{2}\left(v_{j}-v_{j-1}\right)\left(v_{j}+v_{j-1}\right)-M \frac{h_{j}}{2}\left(u_{j}+u_{j-1}\right)$

$-\frac{\alpha h_{j}}{2} f_{j-1 / 2}^{n-1}\left(v_{j}+v_{j-1}\right)+\frac{\alpha h_{j}}{2} v_{j-1 / 2}^{n-1}\left(f_{j}+f_{j-1}\right)=\left[R_{1}\right]_{j-1 / 2}^{n-1}$

$\frac{1}{\operatorname{Pr}}\left(t_{j}-t_{j-1}\right)+D u\left(p_{j}-p_{j-1}\right)+(1+\alpha) \frac{h_{j}}{4}$

$\left(t_{j}+t_{j-1}\right)\left(f_{j}+f_{j-1}\right)-\frac{\alpha h_{j}}{4}\left(u_{j}+u_{j-1}\right)\left(s_{j}+s_{j-1}\right)$

$+\frac{\alpha h_{j}}{2} s_{j-1 / 2}^{n-1}\left(u_{j}+u_{j-1}\right)-\frac{\alpha h_{j}}{2} u_{j-1 / 2}^{n-1}\left(s_{j}+s_{j-1}\right)$

$-\frac{\alpha h_{j}}{2} f_{j-1 / 2}^{n-1}\left(t_{j}+t_{j-1}\right)+\frac{\alpha h_{j}}{2} t_{j-1 / 2}^{n-1}\left(f_{j}+f_{j-1}\right)=\left[R_{2}\right]_{j-1 / 2}^{n-1}$

$\frac{1}{S c}\left(p_{j}-p_{j-1}\right)+S r\left(t_{j}-t_{j-1}\right)+(1+\alpha) \frac{h_{j}}{4}$

$\left(p_{j}+p_{j-1}\right)\left(f_{j}+f_{j-1}\right)-\frac{\alpha h_{j}}{4}\left(u_{j}+u_{j-1}\right)$

$\left(g_{j}+g_{j-1}\right)+\frac{\alpha h_{j}}{2} g_{j-1 / 2}^{n-1}\left(u_{j}+u_{j-1}\right)$

$-\frac{\alpha h_{j}}{2} u_{j-1 / 2}^{n-1}\left(g_{j}+g_{j-1}\right)-\frac{\alpha h_{j}}{2} f_{j-1 / 2}^{n-1}\left(p_{j}+p_{j-1}\right)$

$+\frac{\alpha h_{j}}{2} p_{j-1 / 2}^{n-1}\left(f_{j}+f_{j-1}\right)=\left[R_{3}\right]_{j-1 / 2}^{n-1}$

$\alpha=\frac{\xi^{n-1 / 2}}{k_{n}}$

$f_{0}^{n}=u_{0}^{n}=0, \quad s_{0}^{n}=1, \quad v_{j}^{n}=0, \quad s_{j}^{n}=0$

$\left[R_{1}\right]_{j-1 / 2}^{n-1}=h_{j}\left(\begin{array}{c}(1-m)\left(v^{\prime}\right){ }_{j-1 / 2}^{n-1}-(1-\alpha)\left(u^{2}\right)_{j-1 / 2}^{n-1} \\ +(1-\alpha+\xi \cot \xi) f_{j-1 / 2}^{n-1} v_{j-1 / 2}^{n-1}-M u_{j-1 / 2}^{n-1} \\ +m W e v_{j-1 / 2}^{n-1} v_{j-1 / 2}^{n-1}+B\left(s_{j-1 / 2}^{n-1}+N g_{j-1 / 2}^{n-1}\right)\end{array}\right)$
$\left[R_{2}\right]_{j-1 / 2}^{n-1}=h_{j}\left(\begin{array}{l}\frac{1}{\operatorname{Pr}} t_{j-1 / 2}^{n-1}+(1-\alpha) f_{j-1 / 2}^{n-1} t_{j-1 / 2}^{n-1} \\ +\alpha u_{j-1 / 2}^{n-1} s_{j-1 / 2}^{n-1}+\operatorname{Dup}_{j-1 / 2}^{\prime n-1}\end{array}\right)$

$\left[R_{3}\right]_{j-1 / 2}^{n-1}=h_{j}\left(\begin{array}{l}\frac{1}{S c} p_{j-1 / 2}^{\prime n-1}+(1-\alpha) f_{j-1 / 2}^{n-1} p_{j-1 / 2}^{n-1} \\ +\alpha u_{j-1 / 2}^{n-1} g_{j-1 / 2}^{n-1}+S r t_{j-1 / 2}^{n-1}\end{array}\right)$

The boundary conditions are:

$f_{0}^{n}=u_{0}^{n}=0, \quad s_{0}^{n}=1, \quad v_{j}^{n}=0, \quad s_{j}^{n}=0$

\section{Stage 3: Quasilinearization of Non-linear Keller Algebraic Equations}

Assuming $f_{j}^{n-1}, u_{j}^{n-1}, v_{j}^{n-1}, s_{j}^{n-1}, t_{j}^{n-1}, p_{j}^{n-1}, q_{j}^{n-1}$ to be known for $0 \leq j \leq J$, then equations (12)-(16) constitute a system of $7 \mathrm{~J}+7$ equations for the solutions of $7 \mathrm{~J}+7$ unknowns $f_{j}^{n}, u_{j}^{n}, v_{j}^{n}, s_{j}^{n}, t_{j}^{n}, p_{j}^{n}, q_{j}^{n} j=0,1,2, \ldots, J$. This non-linear system of algebraic equations is linearized by means of Newtonian's method as explained by Keller, (1978) and recently this method is frequently used by Subba Rao et al.(2015), (2016), (2017).

\section{Stage 4: Block-tridiagonal Elimination solution of linear} Keller Algebraic Equations

The linearized system is solved by the block-elimination method, since it possesses a block-tridiagonal structure. The bock-tridiagonal structure generated consists of block matrices. The complete linearized system is formulated as a block matrix system, where each element in the coefficient matrix is a matrix itself, and this system is solved using the efficient Keller-box method. The numerical results are strongly influenced by the number of mesh points in both directions. After some trials in the $\eta$-direction (radial coordinate) a larger number of mesh points are selected whereas in the $\xi$ direction (tangential coordinate) significantly less mesh points are utilized. $\eta_{\max }$ has been set at 15 and this defines an adequately large value at which the prescribed boundary conditions are satisfied. $\xi$ maxis set at 3.0 for this flow domain. Mesh independence is achieved in the present computations. The numerical algorithm is executed in MATLAB on a PC. The method demonstrates excellent stability, convergence and consistency, as elaborated by Keller, 1978.

\section{RESULTS AND DISCUSSIONS}

Comprehensive solutions have been obtained and are presented in Tables and Figures. The numerical problem comprises independent variables $(\xi, \eta)$, dependent fluid dynamic variables $(f, \theta, \xi)$ and thermo-physical and body force control parameters, namely $W e, m, \operatorname{Pr}, S c, M, S r, D u$. The following default parameter values, i.e., $W e=0.3, m=0.3, \operatorname{Pr}=0.71, S c=0.25, \quad M=1.0, N=1.0$ $S r=0.08, D u=0.1 \quad$ (i.eSr.Du $=0.08$ ) are prescribed (unless otherwise stated). Furthermore, the influence of stream wise (transverse) coordinate on heat transfer characteristics is also investigated.

Figures 3(a)-3(c) the dimensionless velocity $f^{\prime}(\eta)$, temperature $\theta(\eta)$ and concentration $\phi(\eta)$ for various values of magnetic parameter $M$ are shown. Fig. 3(a) represents the velocity profile for the different values of magnetic field parameter $M$. It is observed that velocity of the flow decreases significantly throughout the fluid domain with increasing values of magnetic parameter $M$. Application of a magnetic field to an electrically conducting fluid produces a kind of 
drag-like force called Lorentz force. This force cause's reduction in the fluid velocity within the boundary layer as the magnetic field opposes the transport phenomena. In Fig. 3(b), the temperature distribution increases with increasing magnetic values. The effect of Lorentz force on velocity profiles generated a kind of friction on the flow this friction in turn generated more heat energy which eventually increases the temperature distribution in the flow (see Fig. 3(b)). The concentration profile for the fluid has significant increase with increase in the magnetic parameter due to the temperature gradient inherent in the viscosity of the fluid as shown in Fig. 3(c).

Figures 4(a)-4(c) depicts the profiles for velocity $f^{\prime}(\eta)$ and temperature $\theta(\eta)$ and concentration $\phi(\eta)$ for various values of the power law index $m$, It is observed that an increase in $m$ decelerates the flow i.e., velocity, temperature increases. However, increasing $m$ is found to decrease the concentration.

Figures 5(a)-5(c) depict the velocity $f^{\prime}(\eta)$, temperature $\theta(\eta)$ and concentration $\phi(\eta)$ distributions, rise in $N$ clearly induces an increase in velocity as seen in Figure 5(a), the flow is significantly accelerated for $N=2.5$, where once again a velocity overshoot is computed at intermediate distance from the cylinder $(\eta \sim 3)$. For $N=0.5,1.0,1.5$, $2.0,2.5$, no velocity overshoot is apparent although velocities are increased in the regime continuously. In Figure 5(b)for positive $N$ (thermal and concentration buoyancy forces assisting each other), this trend is reversed with a decrease in temperature i.e. cooling of the boundary layer regime. In Figure 5(c), a similar response for the concentration distribution is observed as in the case of the temperature distribution, with $\phi$ values increasing fractionally with positive $N$ values. Opposing buoyancy forces $(N<0)$ therefore enhance species diffusion in the regime whereas aiding buoyancy forces $(N>0)$ inhibit species diffusion in the boundary layer.

Figures 6(a)-6(c) depict the velocity $f^{\prime}(\eta)$, temperature $\theta(\eta)$ and concentration $\phi(\eta)$ distributions for various values of Prandtl numberPr. It is observed that an increase in the Prandtl number significantly decelerates the flow i.e., velocity and temperature decreases. Also increasing Prandtl number is found to upturns the concentration.

Figures 7(a)-7(c) depict the velocity $f^{\prime}(\eta)$, temperature $\theta(\eta)$ and concentration $\phi(\eta)$ distributions for different values of Schmidt number $S c$. It is observed that increases in Schmidt number significantly decelerates the flow i.e., velocity and concentration decreases. Also increases the Schmidt number is found that upturns the temperature.

Figure 8(a)-8(c) shows the velocity $f^{\prime}(\eta)$, temperature $\theta(\eta)$ and concentration $\phi(\eta)$ distributions, the influence of Weissenberg numberWe, on the dimensionless skin friction co-efficient $(1-m) \xi f^{\prime \prime}(\xi, 0)+(m / 2) W e \xi\left(f^{\prime \prime}(\xi, 0)\right)^{2}$, heat transfer rate $\theta(\xi, 0)$ and concentration $\phi(\xi, 0)$ at the sphere surface. It is observed that the dimensionless skin friction is decreased with the increase in We .Absorbed that velocity increases, temperature and concentration are decreases.

Figure 9(a)-9(c) Decreasing Soret number $S r$ (increasing Dufour number $D u$ ) on the temperature and concentration distributions respectively are shown. We study the simultaneous increase (and decrease) of these parameters so that their product remains constant at 0.08. Increasing Dufour number increases in temperature whereas an increase in Soret number cools the fluid i.e. reduces temperature, as observed in Figure 5a. Conversely in Figure 5b, we observe that a rise in $D u$ decreases the concentration values in the boundary layer, whereas a rise in Soret number increases values.

Table 1, 2\&3. Document results for the influence of the Prandtl number $(\operatorname{Pr})$ and the Magnetic parameter $(M)$ and Schmidt number $(S c)$ on skin friction $\left(f^{\prime \prime}(0)\right)$ heat transfer rate $\left(-\theta^{\prime}(0)\right)$ and Share hood number $\left(-\phi^{\prime}(0)\right)$. It has been observed that increasing Pr reduces skin friction and Share hood number but increases heat transfer rate (Nusselt numbers). As increasing $S c$ is found to decrease both the skin friction and heat transfer rate (Nusselt number) increases Share hood number. Also increase the Weissenberg number We found that reduces skin friction but increases heat transfer rate (Nusselt numbers) and Share hood number.

Table4 shows that the comparisons of the various values of $\xi$. In order to verify the accuracy of our present method, we have compared our results with those of Merkin (1977) and Nazar (2002).

Table 1 Skin-friction, Nusselt numbers Sherwood for different values of Pr.

\begin{tabular}{|c|c|c|c|}
\hline $\operatorname{Pr}$ & $f^{\prime \prime}(0)$ & $-\theta^{\prime}(\xi, 0)$ & $-\phi^{\prime}(\xi, 0)$ \\
\hline 1 & 1.1634 & 0.6586 & 0.1283 \\
\hline 5 & 1.0667 & 1.2563 & 0.0063 \\
\hline 7 & 1.0466 & 1.3410 & -0.0309 \\
\hline 10 & 1.0253 & 1.6773 & -0.0784 \\
\hline 20 & 0.9816 & 2.3586 & -0.2150 \\
\hline
\end{tabular}

Table 2 Skin-friction, Nusselt numbers and Sherwood number for different values of Sc.

\begin{tabular}{|c|c|c|c|}
\hline $\mathbf{S c}$ & $f^{\prime \prime}(0)$ & $-\theta^{\prime}(\xi, 0)$ & $-\phi^{\prime}(\xi, 0)$ \\
\hline 0.1 & 1.2036 & 0.5832 & 0.1146 \\
\hline 0.2 & 1.1893 & 0.5738 & 0.1378 \\
\hline 0.25 & 1.1838 & 0.5700 & 0.1470 \\
\hline 0.3 & 1.1790 & 0.5667 & 0.1552 \\
\hline 0.5 & 1.1646 & 0.5563 & 0.1800 \\
\hline
\end{tabular}

Table 3 Skin-friction, Nusselt numbers and Sherwood number for different values of $W e$

\begin{tabular}{|l|l|l|l|}
\hline $\mathrm{We}$ & $f^{\prime \prime}(0)$ & $-\theta^{\prime}(\xi, 0)$ & $-\phi^{\prime}(\xi, 0)$ \\
\hline 0.3 & 1.1838 & 0.5700 & 0.1470 \\
\hline 1.0 & 1.1687 & 0.5729 & 0.1471 \\
\hline 2.0 & 1.1301 & 0.5777 & 0.1472 \\
\hline 3.0 & 1.0385 & 0.5838 & 0.1473 \\
\hline
\end{tabular}

Table 4 Values of the local heat transfer coefficient $\theta^{\prime}(\xi, 0)$ for various values of $\xi$ with $W e=0.0, m=0.0, M=0.0$

\begin{tabular}{|c|c|c|c|}
\hline \multirow{2}{*}{$\xi$} & \multicolumn{3}{|c|}{$-\theta^{\prime}(\xi, 0)$} \\
\cline { 2 - 4 } & Nazar (2002) & Merkin (1977) & Present results \\
\hline $0^{0}$ & 0.4214 & 0.4214 & 0.4215 \\
\hline $30^{0}$ & 0.4161 & 0.4161 & 0.4159 \\
\hline $6^{0}$ & 0.4005 & 0.4007 & 0.4008 \\
\hline $90^{0}$ & 0.3741 & 0.3745 & 0.3749 \\
\hline $120^{0}$ & 0.3355 & 0.3364 & 0.3363 \\
\hline $150^{0}$ & 0.2811 & 0.2825 & 0.2834 \\
\hline $180^{0}$ & 0.1916 & 0.1945 & 0.1950 \\
\hline
\end{tabular}




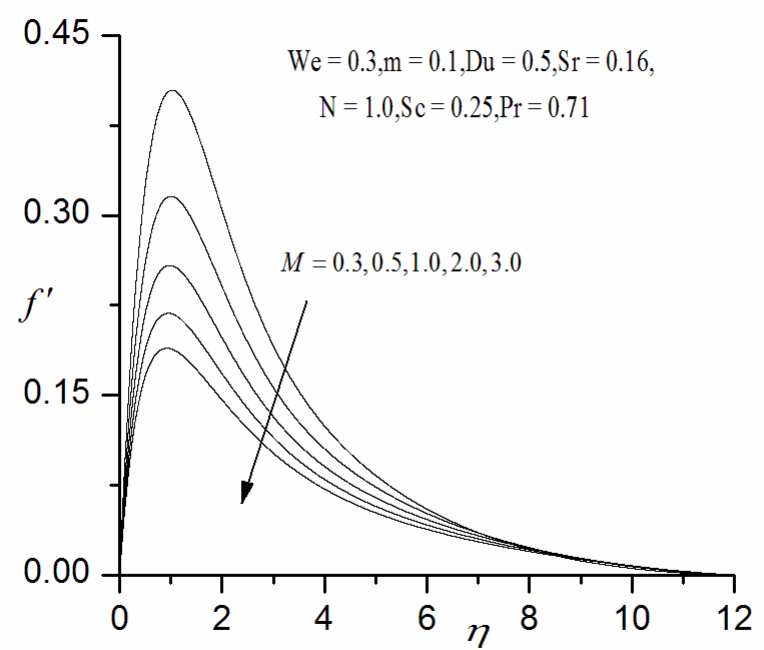

(a)

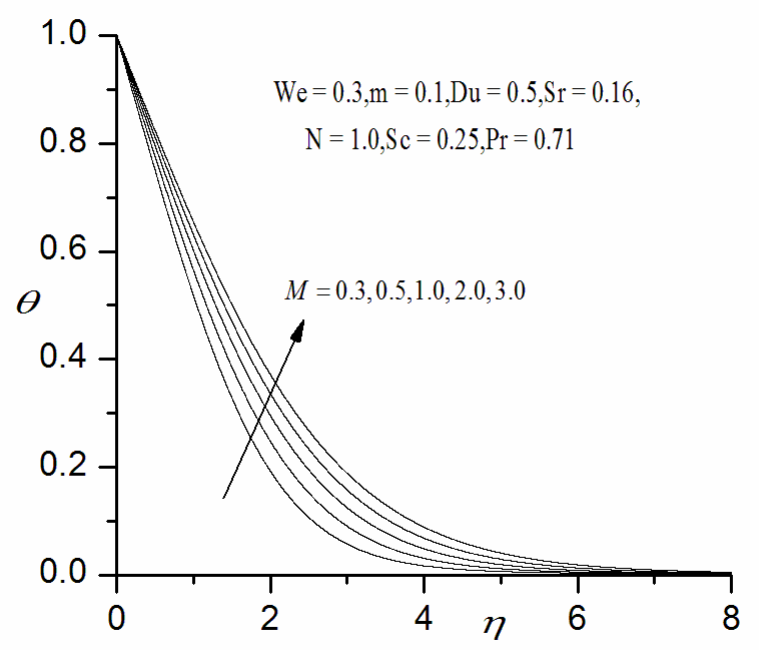

(b)

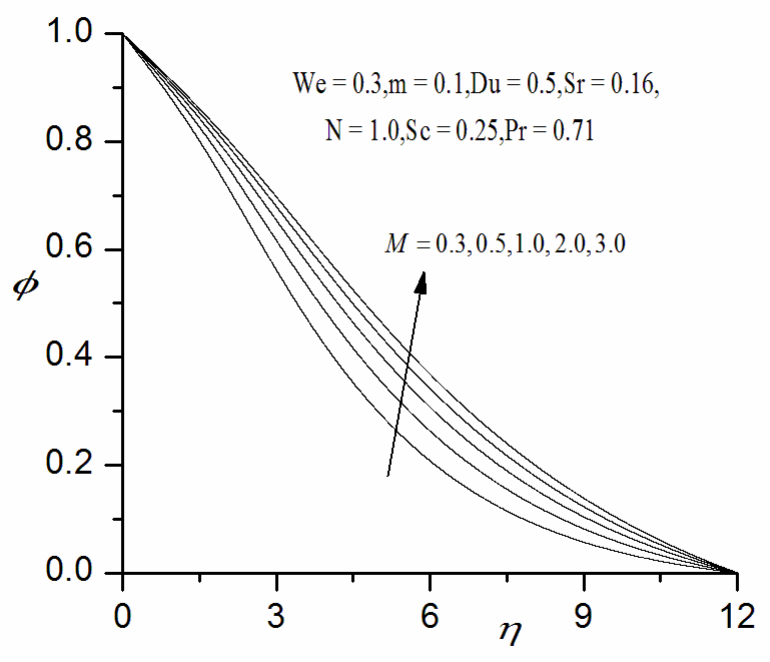

(c)

Fig. 3 Effect of M on (a) Velocity profiles (b) temperature profiles (c) concentration profiles

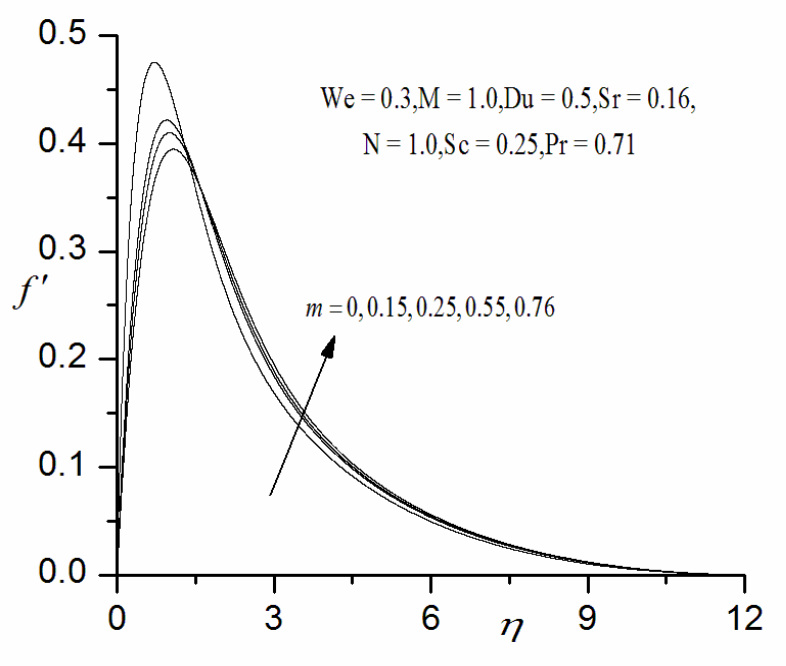

(a)

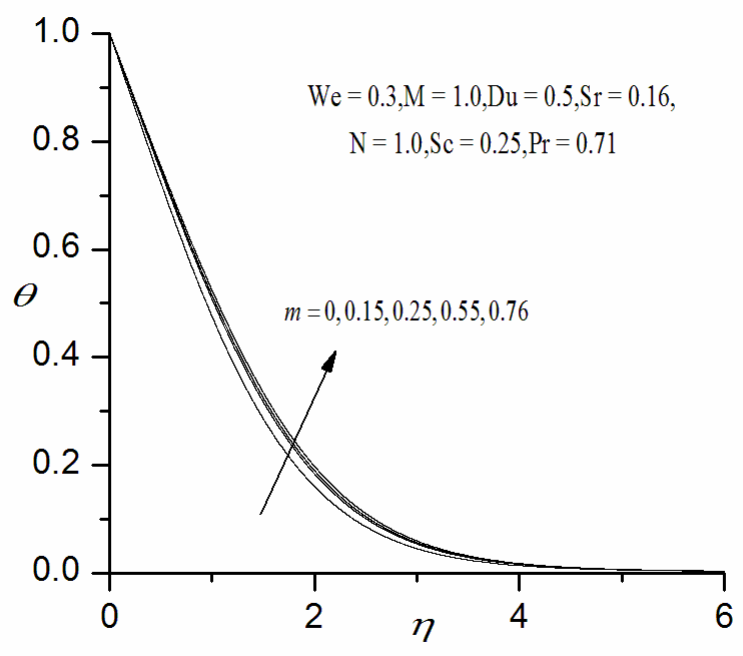

(b)

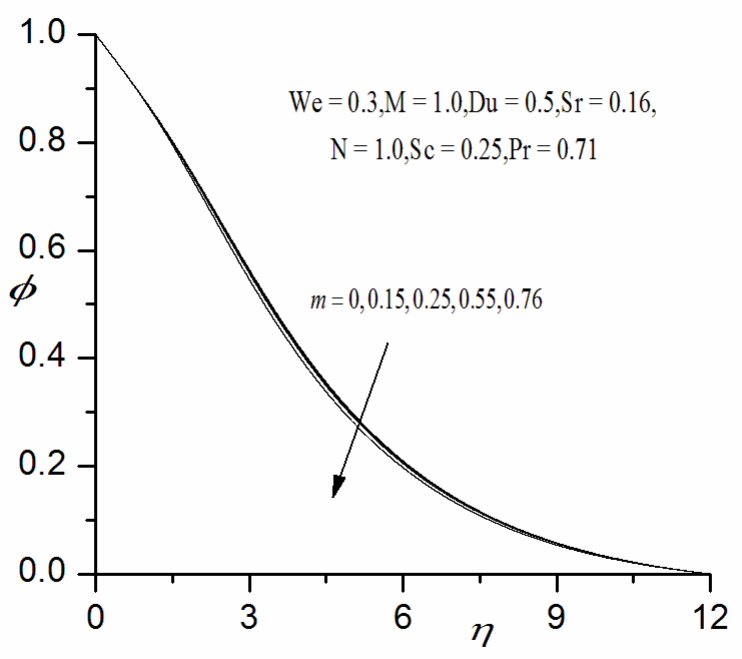

(c)

Fig. 4 Effect of $m$ on (a) Velocity profiles (b) Temperature profiles (c) Concentration profiles 


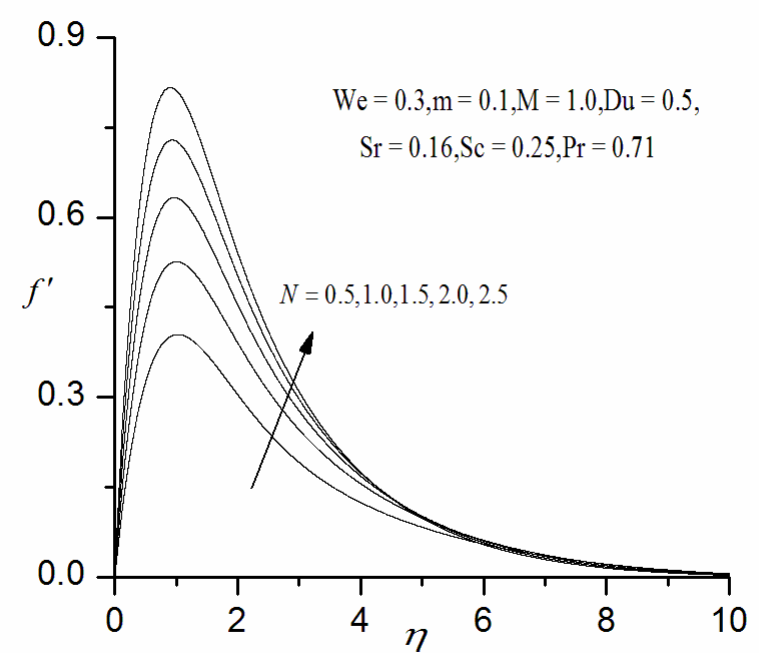

(a)

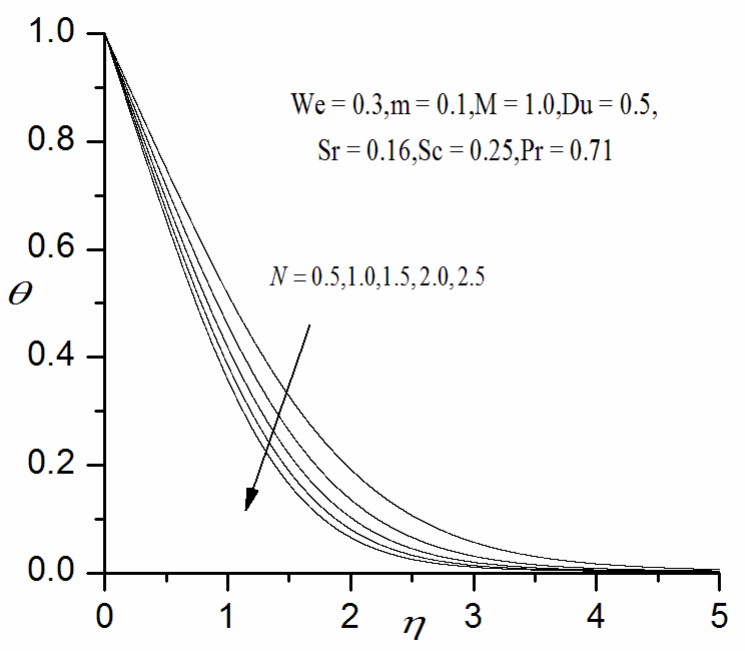

(b)

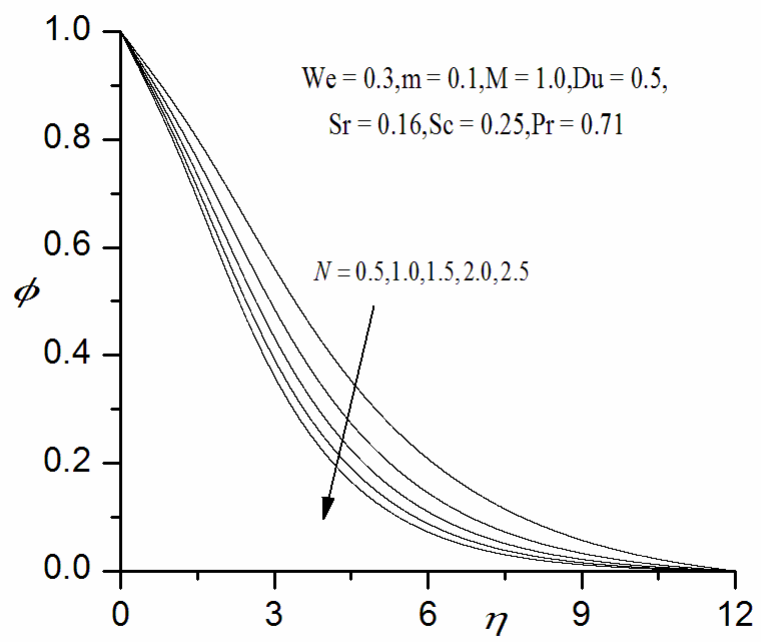

(c)

Fig. 5 Effect of $\mathrm{N}$ on (a) Velocity profiles (b) Temperature profiles (c) Concentration profiles

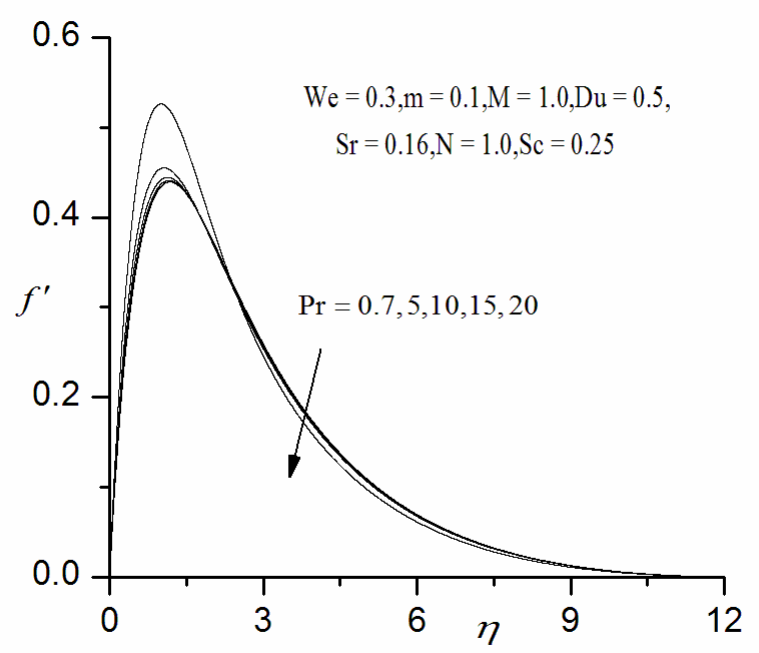

(a)

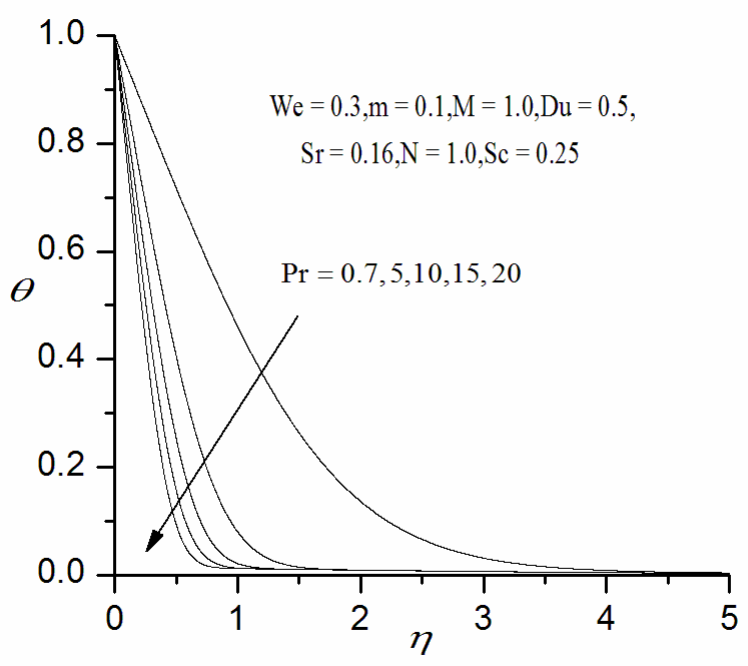

(b)

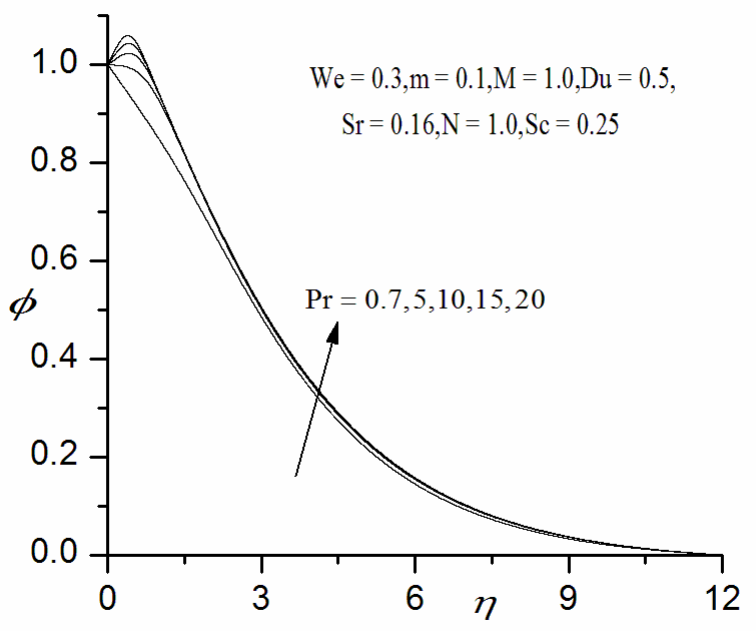

(c)

Fig. 6 Effect of Pr on (a) Velocity profiles (b) Temperature profiles (c) Concentration profiles 


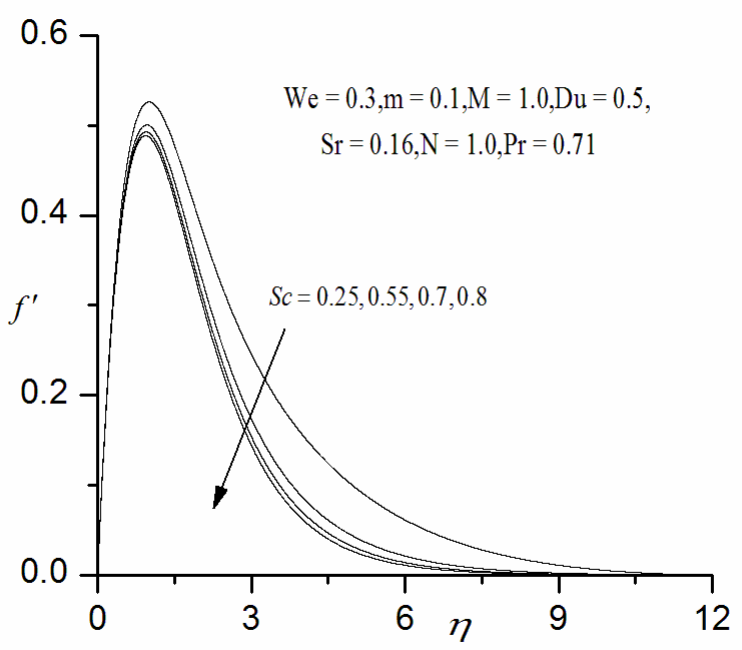

(a)

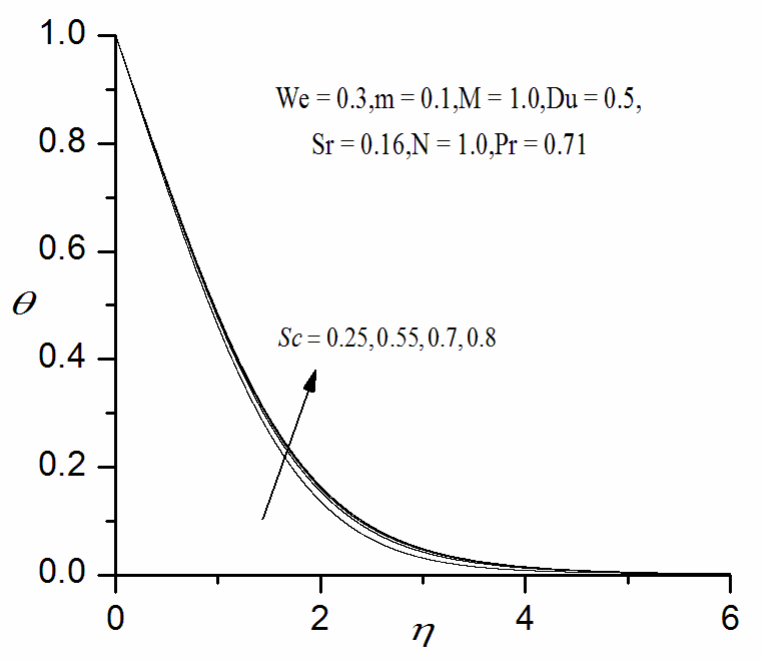

(b)

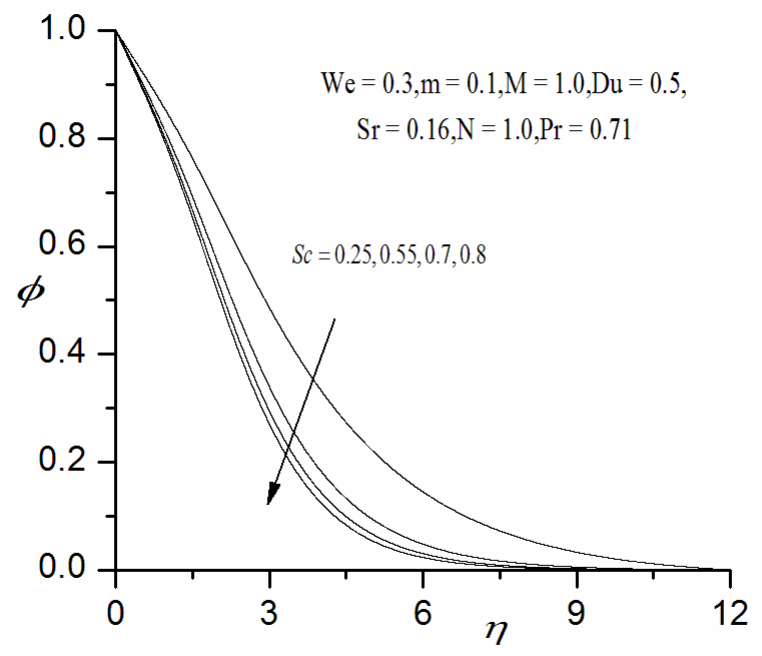

(c)

Fig. 7 Effect of Sc on (a) Velocity profiles (b) Temperature profiles (c) Concentration profiles

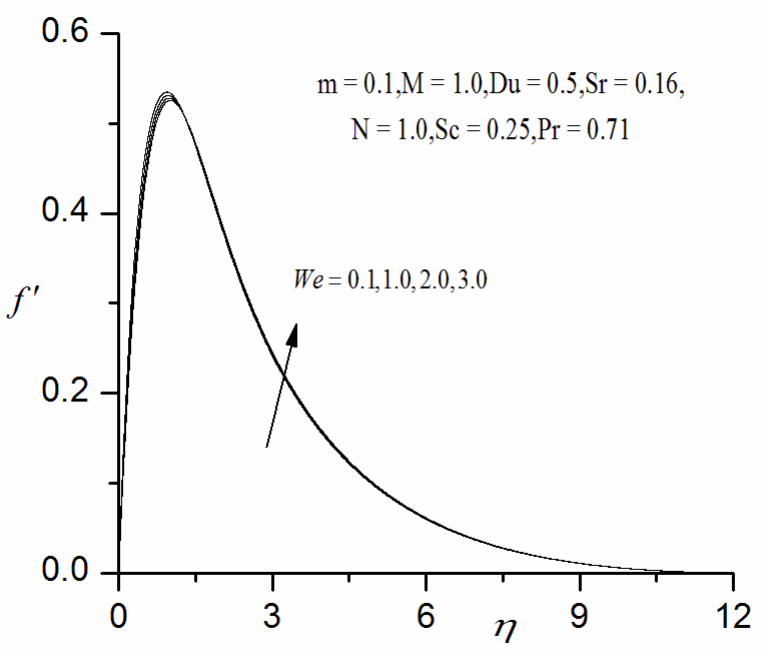

(a)

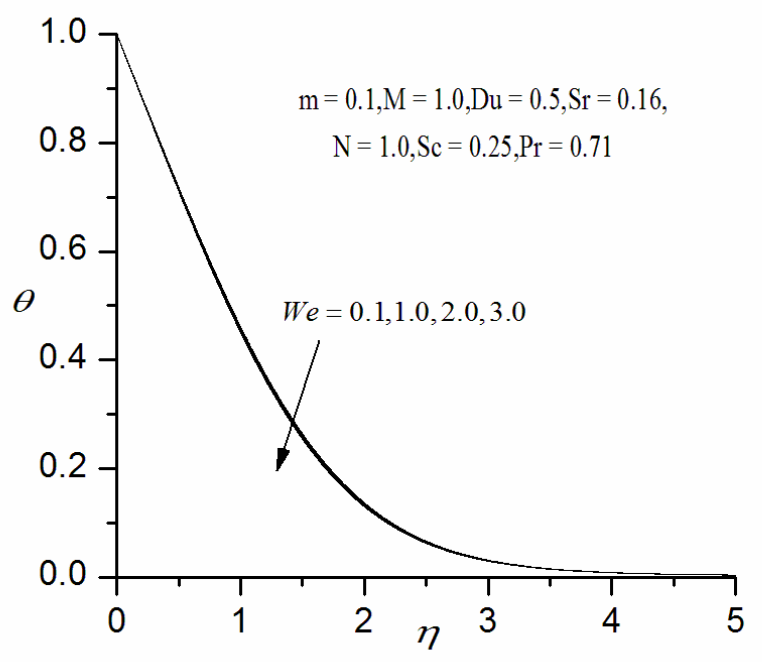

(b)

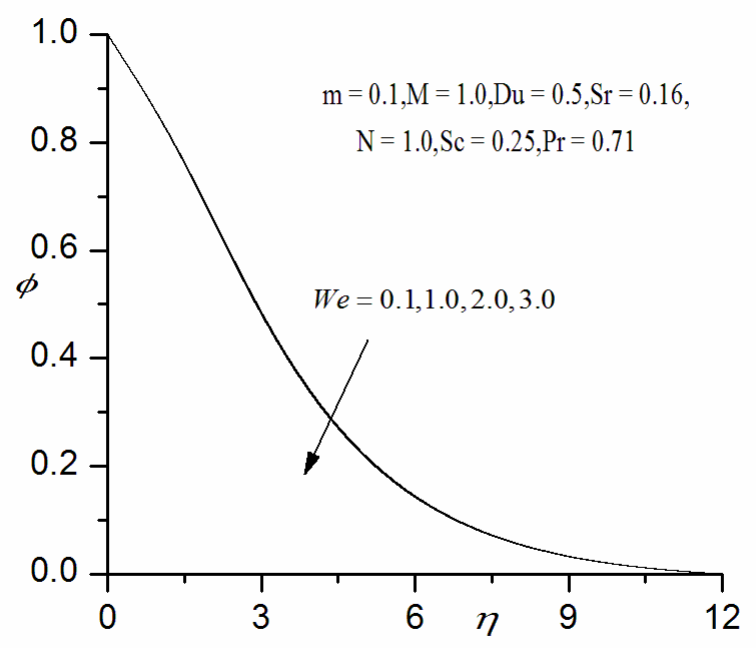

(c)

Fig. 8 Effect of We on (a) Velocity profiles (b) Temperature profiles (c) Concentration profiles 


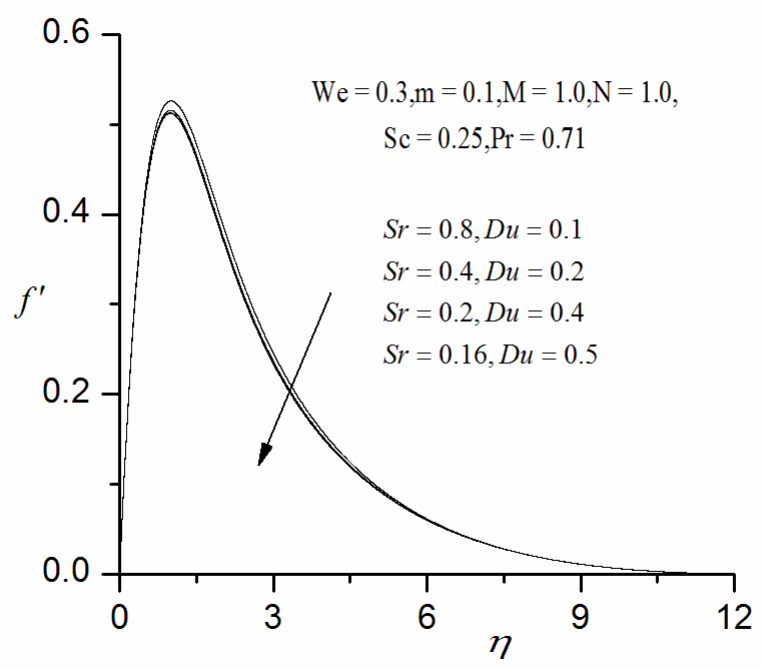

(a)

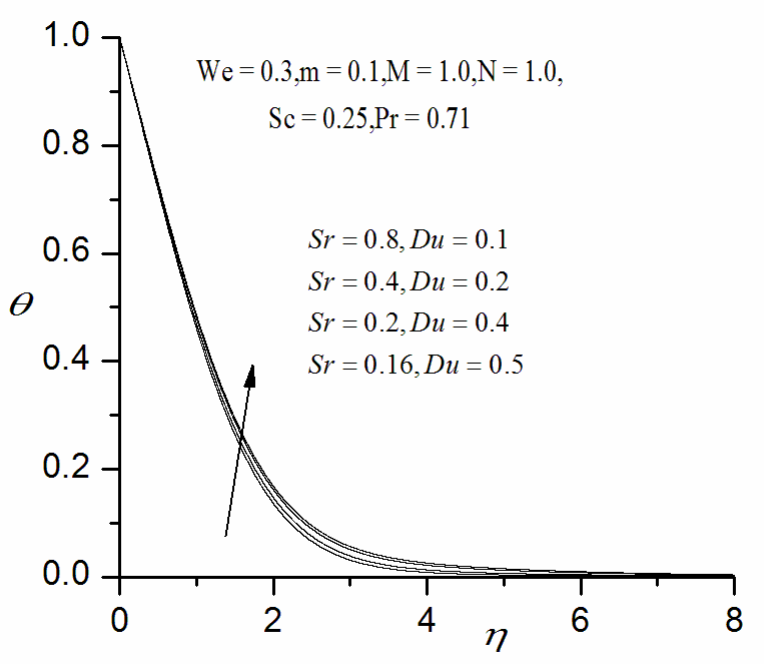

(b)

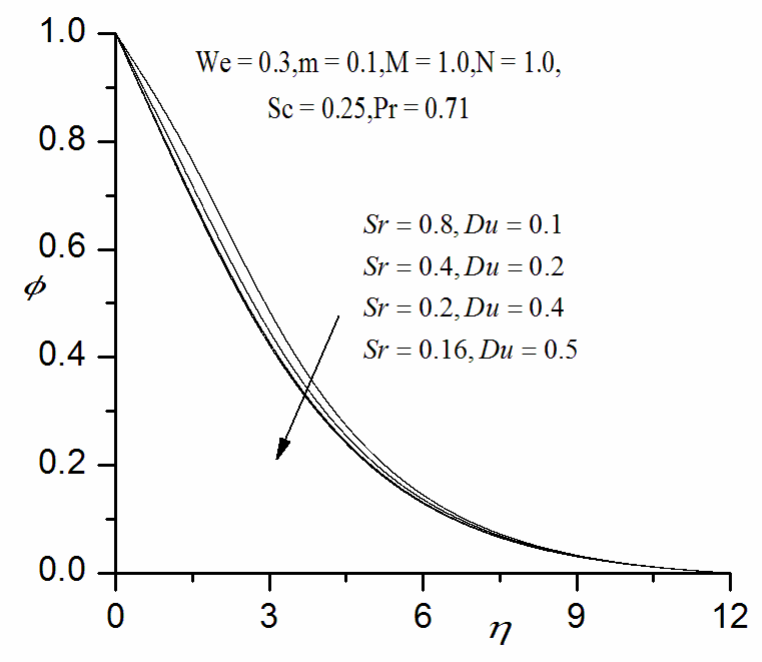

(c)

Fig. 9 Effect of $\mathrm{Sr} \&$ Du on (a) Velocity profiles (b) Temperature profiles (c) Concentration profiles

\section{CONCLUSIONS}

Numerical solutions have been obtained for the free convection heat transfer boundary layer flow along isothermal sphere in the presence of Soret and Dufour effects, using the local non-similarity method and finite difference Keller-Box method.

1. Increasing Weissenberg number We, decreases velocity, skin friction (surface shear stress) and heat transfer rate (Nusselt number), whereas increases temperature.

2. Increasing power law index, $\mathrm{n}$, increases velocity and heat transfer rate, for all values of radial coordinate i.e., throughout the boundary layer regime whereas, decreases temperature and skin friction.

3. Qualitatively opposite behavior is observed for temperature and concentration profiles for Soret and Dufour numbers.

\section{ACKNOWLEDGEMENTS}

The authors appreciate the constructive comments of the reviewers which led to definite improvement in the paper. The corresponding author is thankful to the management of Madanapalle Institute of Technology \& Science, Madanapalle for providing research facilities in the campus.

\section{NOMENCLATURE}

\begin{tabular}{|c|c|}
\hline$C_{f}$ & skin friction coefficient \\
\hline$a$ & radius of the sphere \\
\hline$m$ & power law index \\
\hline$f$ & non-dimensional steam function \\
\hline$G r$ & Grashof number \\
\hline$g$ & acceleration due to gravity \\
\hline$k$ & thermal conductivity of fluid \\
\hline$N u$ & local Nusselt number \\
\hline$S r$ & Soret number \\
\hline$D u$ & Dufour number \\
\hline $\operatorname{Pr}$ & Prandtl number \\
\hline We & Weissenberg number \\
\hline $\mathrm{T}$ & temperature of the fluid \\
\hline$r(x)$ & $\begin{array}{l}\text { Radial distance from symmetrical axis to surface ofthe sphere } \\
\text { surface of the sphere }\end{array}$ \\
\hline $\mathrm{u}, \mathrm{v}$ & $\begin{array}{l}\text { non-dimensional velocity components along the } x-\text { and } y \text { - } \\
\text { directions, respectively }\end{array}$ \\
\hline$V$ & $\begin{array}{l}\text { velocity vector } \mathrm{x} \text { stream wise coordinate } \mathrm{y} \text { transverse } \\
\text { coordinate }\end{array}$ \\
\hline$x$ & Stream wise coordinate \\
\hline$y$ & Transverse coordinate thermal diffusivity \\
\hline \multicolumn{2}{|c|}{ Greek symbols } \\
\hline$\alpha$ & thermal diffusivity \\
\hline$\beta$ & fluid parameter \\
\hline$\delta$ & local non-Newtonian parameter \\
\hline$\eta$ & dimensionless radial coordinate \\
\hline$\mu$ & dynamic viscosity \\
\hline$v$ & kinematic viscosity \\
\hline$\theta$ & dimensionless temperature \\
\hline$\rho$ & density of non-Newtonian fluid \\
\hline & dimensionless tangential coordinate \\
\hline
\end{tabular}


$\psi \quad$ dimensionless stream function

$\varepsilon \quad$ fluid parameter

\section{Subscripts}

W condition at the wall

$\infty \quad$ free stream condition

\section{REFERENCES}

Ali Abbas. M, Bai. Y.Q., Bhatti. M.M., Rashidi. M.M., 2016, “Three Dimensional Peristaltic Flow of Hyperbolic Tangent Fluid in Nonuniform Channel Having Flexible Walls," Alexandria Engineering Journal, 55, 653-662.

http://dx.doi.org/10.1016/j.aej.2015.10.012

Cheng C.Y., 2015, "Natural Convection Heat Transfer about a Vertical Cone Embedded in a Tridisperse Porous Media with Constant Wall Temperature," Transport in porous media, 107, 765-779.

Cheng C.Y., 2015, "Free Convection Heat Transfer from a NonIsothermal Permeable Cone with Suction and Temperature-Dependent Viscosity," J. Applied Science and Engineering, 18, 17-24.

Gorla R. S. R., Schoren W. R. and Takhar H. S., 1986, "Natural Convection Boundary Layer Flow of a Micropolar Fluid Over an Isothermal Cone," Acta Mechanica, 61, 139-152.

Hayat T, Yasmin.H, Yami. M.A., 2014, "Soret and Dufour Effects in Peristaltic Transport of Physiological Fluids with Chemical Reaction: A Mathematical Analysis," Computers and Fluids, 89, 242-253.

http://dx.doi.org/10.1016/j.compfluid.2013.10.038

Landau L.D. and Levich B., 1942, "Dragging of Liquid by a Plate," Acta Physiochim, USSR, 17, 42-54.

http://10.1016/B978-0-08-092523-3.50016-2

Lawrence C.J, Zhou W, 1991, "Spin Coating of Non-Newtonian Fluids," J. Non-Newtonian Fluid Mechanics, 39, 137-187.

Keller. H.B., 1978, "Numerical Methods in Boundary-Layer Theory Annual Review of Fluid Mechanics," 10, 417-433.

http://10.1146/annurve.fl.10.010178.002221

Mark J.E., 1996, "Physical Properties of Polymers Handbook", AIP Press, Woodbury, New York, USA.

Merkin, J.H. 1977, "Free Convection Boundary Layers on Cylinders of Elliptic Cross Section,” J. Heat Transf. 99, 453-457.

http://10.1115/1.3450717

Mitsoulis E., 1986, "Fluid Flow and Heat Transfer in Wire Coating: A Review," Advances in Polymer Technology, 6, 467-487.

Muhammad Naseer, Muhammad Yousaf Malik, Sohail Nadeem, Abdul Rehman, 2014, "The Boundary Layer Flow of Hyperbolic Tangent Fluid Over a Vertical Exponentially Stretching Cylinder," Alexandria Engineering Journal, 53, 747-750.

http://dx.doi.org/10.1016/i.aej.2014.05.001

Nadeem. S., Hina Sadaf, Noreen Sher Akbar, 2015, "Effects of Nanoparticles on the Peristaltic Motion of Tangent Hyperbolic Fluid Model in an Annulus," Alexandria Engineering Journal, 54, 843-851. http://dx.doi.org/10.1016/j.aej.2015.07.003

Nazar, R., Amin, N., Pop, I. 2002, "Free Convection Boundary Layer on an Isothermal Horizontal Circular Cylinder in a Micropolar Fluid, Heat Transfer," Proceeding of the 12th International Conference

Osvaldo Campanella H., Jorge L. Galazzo, Ramón L. 1986, “Cerro, Viscous Flow on The Outside of a Horizontal Rotating Cylinder-II.
Dip Coating With a Non-Newtonian Fluid," Chemical Engineering Science, 41, 2707-2713.

Panigrahi. S., Reza. M., Mishra. A.K., 2014, "MHD Effect of Mixed Convection Boundary-Layer Flow of Powell-Eyring Fluid past Nonlinear Stretching Surface," Applied Mathematics and Mechanics 35, 1525-1540. http://10.1007/s10483-014-1888-6

Pop.I, Ingham. D.B, 2001, "Convective Heat Transfer: Mathematical and Computational Modelling of Viscous Fluids and Porous Media," Pergamum, Amsterdam, New York.

Prasad V. R., Subba Rao A., Bhaskar Reddy N., Vasu B and Anwar Beg O., 2013, "Modelling Laminar Transport Phenomena in a Casson Rheological Fluid From a Horizontal Circular Cylinder With Partial Slip," J. Process Mechanical Engineering, 227, 309-326.

Qasim. M., 2014, "Soret and Dufour Effects on The Flow of an EyringPowell fluid Over a Flat Plate with Convective Boundary Condition," Eur. Phys. J. Plus, 129, 1-7.

http://10.1140/epjp/i2014-14024-4

Salahuddin. T. Malik.M.Y., Arif Hussain, Bilal. S and Awais. M., 2015 "Effects of Transverse Magnetic Field with Variable Thermal Conductivity on Tangent Hyperbolic Fluid with Exponentially Varying Viscosity," AIP advances, 5,127103.

http://dx.doi.org/10.1063/1.4937366

Samson Jenekhe A., Spencer B. Schuldt, 1984, "Coating Flow of NonNewtonian Fluids on a Flat Rotating Disk", Ind. Eng. Chem. Fundamen., 23, 432-436.

Satya Narayana. P.V., Harish Babu. D., 2016, "Joule Heating Effects on MHD Mixed Convection of a Jeffrey Fluid Over a Stretching Sheet With Power Law Heat Flux: A Numerical Study," Journal of Magnetism and Magnetic Materials, 412 ,185-193.

http://dx.doi.org/10.1016/i.jmmm.2016.04.011

Subba Rao. A., Ramachandra Prasad V., Nagendra. N, Bhaskar Reddy. $\mathrm{N}$ and Anwar Bég O. 2016, "Non-Similar Computational Solution for Boundary Layer Flows of Non-Newtonian Fluid From an Inclined Plate with Thermal Slip," J. Applied Fluid Mechanics, 9, 795-807.

Subba Rao. A, V.R. Prasad, N. Bhaskar Reddy, O. Anwar Beg, 2015, "Modelling Laminar Transport Phenomena in a Casson Rheological Fluid from a Semi-Infinite Vertical Plate With Partial Slip," Heat Transfer-Asian Research, 44, 272-291,

http://10.1002/htj.21115

Subba Rao. A, V.R. Prasad, N. Bhaskar Reddy and O. Anwar Beg,2015, "Modelling Laminar Transport Phenomena In A Casson Rheological Fluid From An Isothermal Sphere With Partial Slip," Thermal science, 19, 1507-1519; http://10.2298/TSCI120828098S

Subba Rao. A, V.R.Prasad, K. Harshavalli and O. Anwar Beg, 2016, "Thermal Radiation Effects on Non-Newtonian Fluid in a Variable Porosity Regime with Partial Slip," J. Porous Media, 19, 313-329.

Subba Rao. A, V. R. Prasad, V. Nagaradhika, O. Anwar Beg, 2017, "Heat Transfer in Viscoplastic Boundary Layer Flow from a Vertical Permeable Cone with Momentum and Thermal Wall Slip: Numerical Study," Heat Transfer Research, (In Press).

Subba Rao A., V. R Prasad, O. Anwar Beg and M. Rashidi, 2017, "Free Convection Heat and Mass Transfer of a Nanofluid Past a Horizontal Cylinder Embedded in a Non-Darcy Porous Medium," Journal of Porous Media, (In Press). 
Subba Rao A, Ramachandra Prasad V, Rajendra P, Sasikala M, Anwar Beg O,2017, "Numerical Study of Non-Newtonian Polymeric Boundary Layer Flow And Heat Transfer From a Permeable Horizontal Isothermal Cylinder," Frontiers in Heat and Mass Transfer, 9, 2, 1-9. http://dx.doi.org/10.5098/hmt.9.2

Sulochana C., Ashwinkumar. G. P. and Sandeep. N., 2016, "Magneto Hydrodynamic Flow towards a Vertical Rotating Cone in Porous Medium with Thermophoresis and Brownian Motion Effects," Int. J. Advanced Science and Technology, 86, 61-74.

Yih. K.A., 2000, "Viscous and Joule Heating Effects on Non-Darcy MHD Natural Convection Flow over a Permeable Sphere in Porous
Media with Internal Heat Generation," International Communications in Heat and mass Transfer, 27, 591-600.

http://dx.doi.org/10.1016/S0735-1933(00)00141-X

Yih K.A., 1999, "Effect of Radiation on Natural Convection about a Truncated Cone," Int. J. Heat Mass Transfer, 42, 4299-4305. http://10.1016/S0017-9310(99)00092-7

Zevallos G.A., Carvalhoa M.S., Pasquali M. 2005, "Forward Roll Coating Fows of Viscoelastic Liquids," J. Non-Newtonian Fluid Mech., 130, 96-109.

http://10.1016/j.jnnfm.2005.08.005 